\title{
Molecular Biology of the Type I Human T-Cell Leukemia Virus (HTLV-I) and Adult T-Cell Leukemia
}

\author{
Matthew R. Smith and Warner C. Greene \\ Howard Hughes Medical Institute, Departments of Medicine, and Microbiology and Immunology, \\ Duke University Medical Center, Durham, North Carolina 27710
}

\section{Introduction}

The two major recognized pathogenic human retroviruses, the type I human T-cell leukemia virus (HTLV-I) ${ }^{1}$ and the type 1 human immunodeficiency virus (HIV-1), are distinguished from most other animal retroviruses by their striking genomic complexity. Although only distantly related, HTLV-I and HIV-1 utilize remarkably similar strategies for the regulation of viral gene expression. Specifically, both viruses encode essential trans-regulatory proteins that markedly increase expression of all viral gene products (HTLV-I Tax and HIV-1 Tat) as well as distinct viral polypeptides that selectively activate the expression of viral structural genes (HTLV-I Rex and HIV-1 Rev) (1). These different trans-regulatory proteins not only play central roles in the life cycles of HTLV-I and HIV-1 but also contribute importantly to the disease processes induced by these viral pathogens. In the following review, we discuss the molecular biology of HTLV-I, highlighting recent studies that provide important insights into the mechanisms of action of the Tax and Rex trans-regulatory proteins.

HTLV-I is recognized as the etiologic agent of the adult T-cell leukemia/lymphoma (ATLL) $(2,3)$. ATLL is an often aggressive and fatal malignancy of mature $\mathrm{CD} 4^{+} \mathrm{T}$ lymphocytes. This neoplasm occurs in geographic regions of the world where HTLV-I infection is endemic, including southern Japan, sub-Saharan Africa, the Caribbean basin, and the southeastern United States. Clinically, ATLL is characterized by leukemia, lymphadenopathy, tumor infiltrates of the skin, hepatosplenomegaly, hypercalcemia, and lytic bone lesions (4). HTLV-I is transmitted horizontally by sexual intercourse and exposure to contaminated blood or cellular blood products. Vertical transmission from mother to child has also been documented. The period between infection and onset of clinical disease in HTLV-I-infected individuals is typically quite long, often ranging between 10 and 30 years. Further, the rate of HTLV-I associated malignancy among seropositive individuals is rela-

\footnotetext{
Address reprint requests to Dr. Greene, Box 3037, Duke University Medical Center, Durham, NC 27710.

Received for publication 26 October 1990.
}

1. Abbreviations used in this paper: ATF, activating transcription factor; ATLL, adult T-cell leukemia/lymphoma; CREB, cyclic AMP response element binding protein; HTLV-I, type I human T-cell leukemia virus; LTR, long terminal repeats; RE, response element(s).

J. Clin. Invest.

(c) The American Society for Clinical Investigation, Inc.

0021-9738/91/03/0761/06 \$2.00

Volume 87, March 1991, 761-766 tively low ( $<5 \%$ lifetime risk). However, the prognosis for patients who develop the acute form of ATLL is extremely poor with few surviving beyond 6 months.

More recently, HTLV-I has been associated with a chronic neurodegenerative syndrome termed HTLV-I-associated myelopathy or tropical spastic paraparesis $(5,6)$. This syndrome is characterized by the progressive demyelination of long motor neuron tracts in the spinal cord leading to spasticity, paraparesis, and decreased muscle strength. Multiple sclerosis, a far more prevalent neurologic disease, shares certain clinical features with HTLV-I-associated myelopathy/tropical spastic paraparesis. However, the role of HTLV-I or related retroviruses in multiple sclerosis remains controversial (7).

HTLV-II is a closely related human retrovirus that has been associated with only rare cases of a clinically benign T-cell variant of hairy cell leukemia $(8,9)$. Therefore, a clear role of HTLV-II in human malignancy has not yet been established. In contrast to HTLV-I, no endemic region for HTLV-II has been identified. Of note, recent studies employing polymerase chain reaction (PCR) methodology have revealed that HTLVII infection is particularly prevalent among certain populations of intravenous drug abusers in the United States (10). Previously, many of these individuals were thought to be infected with HTLV-I.

HTLV-I appears to induce the leukemic transformation of $T$ cells by a novel mechanism. Unlike acutely transforming animal retroviruses, the HTLV-I genome does not encode a known oncogene (11). Further, this retrovirus does not transform $\mathrm{T}$ cells by cis-activation of an adjacent proto-oncogene, since the provirus appears to integrate randomly within the host genome (12). An interesting property of all long-term cell lines derived from ATLL patients or established by HTLV-I infection of normal $\mathrm{T}$ cells in vitro is the constitutive high level expression of receptors for the $\mathrm{T}$-cell growth factor, interleukin 2 (IL-2) $(13,14)$. The constitutive display of this inducible growth factor receptor complex may contribute to the early polyclonal proliferation of $\mathrm{T}$ cells that characterizes an early stage of HTLV-I infection. However, the primary tumor cells from patients with ATLL are typically monoclonal, suggesting that additional cellular events are required for the completion of the transformation process. The nature of these additional events remain unknown.

\section{Genomic organization of HTLV-I}

Important insights into the pathophysiology of HTLV-I have emerged with the molecular analysis of various proviral isolates. The genomic organization of HTLV-I provirus is shown schematically in Fig. 1. As is characteristic of all replication competent retroviruses, HTLV-I encodes functional $\mathrm{gag}$, pol, 


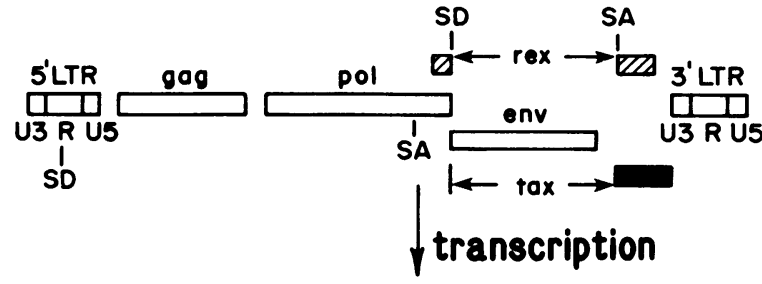

unspliced, primary genomic transcript
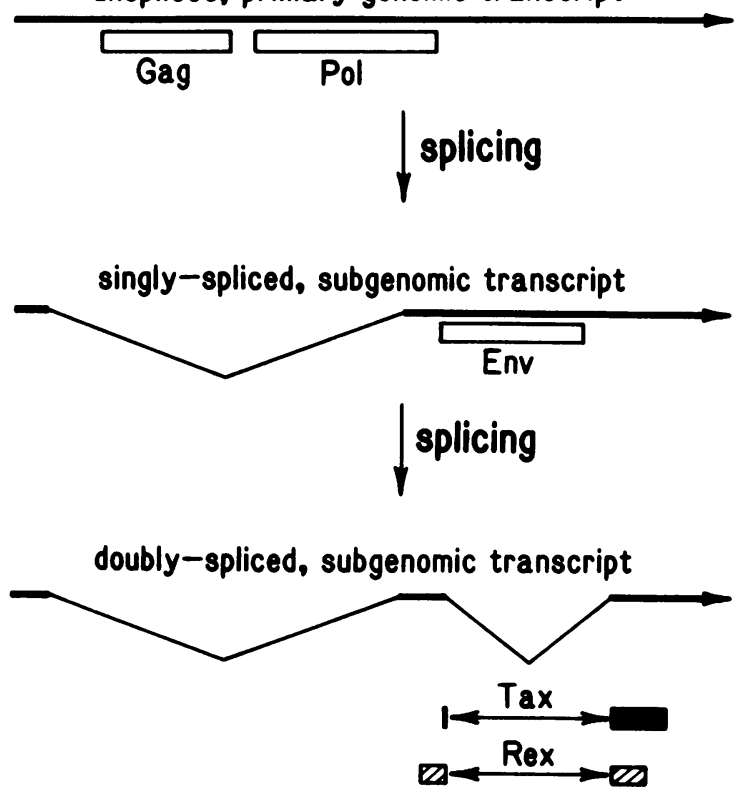

Figure 1. Genomic organization of the HTLV-I provirus. The coding regions of the HTLV-I genes are indicated by the labeled boxes. Sequences critical for the regulation of viral gene expression are contained in the $5^{\prime}$ and $3^{\prime}$ (LTRs). Transcription of the provirus results in a primary genomic mRNA transcript. Subsequent splicing events generate singly spliced and doubly spliced subgenomic transcripts. The position of the splice donors (SD) and splice acceptors (SA) involved in the generation of these spliced mRNA species are indicated.

and $e n v$ gene products and contains tandem long terminal repeats (LTRs) at the $5^{\prime}$ and $3^{\prime}$ ends of its proviral genome. In addition, the novel $3^{\prime}$ or $\mathrm{pX}$ region of provirus encodes two trans-regulatory proteins, termed Tax and Rex (11). Although no infectious HTLV-I proviral clone has yet been isolated, mutational analyses of an infectious clone of HTLV-II have demonstrated that both tax and rex are essential for viral replication (15). Structurally distinct but functionally analogous genes, tat and rev, have been identified in HIV-1 (1).

The HTLV-I gene products are translated from three major mRNA species (Fig. 1). The full-length genomic mRNA encodes the gag and pol gene products, while a singly spliced subgenomic mRNA encodes the Env protein. A doubly spliced mRNA encodes the Tax and Rex trans-regulatory proteins from different reading frames. The Tax protein may be preferentially translated from this short transcript, since the sequences surrounding its methionine initiation codon share greater similarity to the consensus sequences for translational initiation than do-the corresponding sequences in the rex open reading frame.
The Tax protein: a potential mediator of T-cell transformation

The tax gene encodes a 40-kD nuclear phosphoprotein. Tax is a potent trans-activator of viral transcription (16). Tax also transcriptionally activates the expression of certain cellular genes including IL-2, the $\alpha$ chain of the IL-2 receptor (IL-2R $\alpha$ ), and the c-fox proto-oncogene (17-19) (Fig. 2). The central role of these genes in normal T-cell activation and growth suggests that Tax activation of these cellular transcription units may represent an important mechanism by which HTLV-I initiates T-cell transformation. Tax also activates the LTR of HIV-1 (20), which may contribute to the enhanced HIV-1 gene expression detected in T cells dually infected with HTLV-I and HIV-1.

Several lines of evidence suggest that the Tax protein has the ability to initiate cellular transformation. Specifically, introduction of the $\mathrm{pX}$ region of HTLV-I into primary T cells via a nontransforming Herpesvirus saimiri vector resulted in the constitutive high level expression of functional IL-2 receptors. In sharp contrast to normal activated $T$ cells, these $p X$-expressing $\mathrm{T}$ lymphocytes can be maintained in continuous long-term culture in the presence of exogenous IL-2 (21). These intriguing results suggest that the HTLV-I pX gene products may deregulate the normal transient nature of the T-cell growth response. Additionally, transgenic mice expressing the tax gene develop multiple mesenchymal tumors and neurofibromas (22). Not all lines of tax transgenic mice developed these tumors, however, and none of these tax transgenic mice developed leukemia or

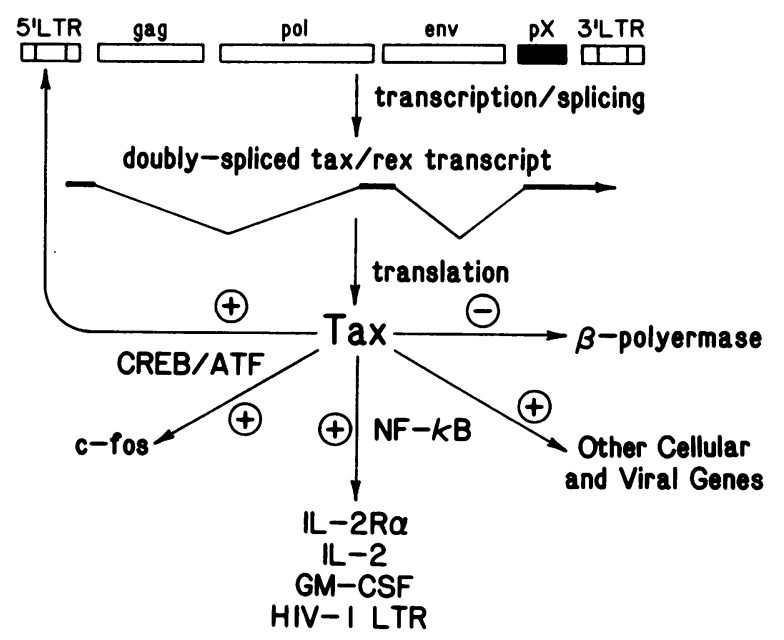

Figure 2. Tax increases transcription of viral and cellular genes through at least two host transcription factor pathways. The Tax protein is encoded in the $\mathrm{pX}$ region of the HTLV-I provirus and is translated from the doubly spliced tax/rex transcript. Tax transactivation HTLV-I genes and the proto-oncogene c-fos appears to involve the modification of CREB/ATF transcription factor(s) that bind to the HTLV-I LTR and the c-fos promoter. By a distinct mechanism, Tax induces the nuclear expression of the pleiotropic transcription factor NF- $\mathrm{kB}$ and activates transcription of a variety of cellular and heterologous viral promoters that contain NF- $\mathrm{B} B$ enhancer elements. These include the promoters of the IL-2, IL-2R $\alpha$, and granulocyte/macrophage colony-stimulating factor genes and the LTR of HIV-1. In addition to its positive transcriptional effects, Tax represses the expression of at least one cellular gene, $\beta$-polymerase, an enzyme involved in DNA repair. 
lymphoma. The ability of Tax to transform nonlymphoid cells has also been demonstrated in other experimental systems. The tax gene, when overexpressed with the ras oncogene, immortalized primary rat fibroblasts (23). Similarly, the stable expression of tax gene alone in an established rat fibroblast cell line (Rat-1) resulted in the transformation of these cells (24).

An attractive model for ATLL includes an early period of Tax-induced polyclonal T-cell proliferation, mediated by the deregulated expression of IL-2 and its receptor. This polyclonal proliferation may in turn facilitate the occurrence of additional events leading to the completion of the transformation process and the monoclonal outgrowth of an IL-2-independent population of leukemic T cells. Since no satisfactory in vitro or animal model of ATLL currently exists, the nature of these later events remains undefined. However, recent studies have demonstrated that Tax represses the expression of $\beta$-polymerase, an enzyme involved in DNA repair (25). Notably, ATLL cells are characterized by chromosomal breaks and other karyotypic abnormalities. Although it remains unknown whether these chromosomal derangements are primary or secondary events in the cellular transformation process, these results raise the possibility that Tax may mediate certain additional cellular events required for T-cell transformation. Notably, ATLL is distinguished from leukemia induced by most other replication competent retroviruses by both the lack of chronic viremia and absence of detectable expression of viral genes. Therefore, while it seems likely that Tax may play an important role in the development of ATLL, neither Tax nor other viral gene products may be required for the maintenance of this transformed phenotype.

Tax activates transcription of cellular and viral genes though at least two distinct host transcription factor pathways. Tax trans-activation of HTLV-I gene expression requires three 21-basepair enhancer elements located in the LTR. Tax does not bind directly to these enhancer elements. Rather, Tax trans-activation of the HTLV-I LTR appears to be mediated through constitutively expressed cellular factors that bind to an octanucleotide core element (TGACGTCT) present within these 21-basepair enhancer elements (26). This octanucleotide motif has been previously identified as a transcriptional regulatory element present in a wide variety of viral and cellular genes including cAMP-inducible genes and the Ela-activated early genes of adenovirus. Tax trans-activation of the HTLV-I LTR likely involves modification of the proteins that binds to this core element. These proteins appear to represent members of the cAMP response element binding protein (CREB) and activating transcription factor (ATF) family of transcription factors. The Tax responsive sequences in the c-fos promoter also contain this octanucleotide motif (19), raising the possibility that Tax activation of both the HTLV-I LTR and c-fos promoter may involve the same host transcription factors.

Tax activation of other cellular and viral promoters, including the promoters of the IL- 2 and IL-2R $\alpha$ genes and the HIV-1 LTR, involves the induced nuclear expression of the pleiotropic transcription factor NF- $\kappa B$ (27). NF- $\kappa$ B was described initially as a constitutively expressed DNA binding protein in mature B cells that specifically bound to the enhancer of the $k$ immunoglobulin light chain gene. However, subsequent studies have revealed that NF- $\mathrm{BB}$ is an inducible transcription factor that regulates the expression of a large number of genes in many different cell types. NF- $\kappa$ B binding activity is regulated by a novel post-translational mechanism involving its sequestration in the cytoplasm by an inhibitor protein termed $I_{\kappa} B$ (28). After normal cellular activation, protein kinase-mediated phosphorylation of $I_{\kappa} B$ results in the dissociation of the cytoplasmic NF- $\kappa$ B-I $\kappa$ B complex (29). Subsequently, NF- $\kappa$ B translocates to the nucleus where it exerts its transcriptional effects. Whether Tax activation of NF- $\kappa$ B involves the phosphorylation of $I_{\kappa} B$ or proceeds by a separate mechanism remains unknown.

Recently, NF- $\kappa \mathrm{B}$ has been established as a member of the rel family of proteins. The gene encoding the 50-kD DNAbinding subunit of NF- $\kappa$ B has been molecularly cloned and sequence analysis has revealed a remarkable sequence homology with the v-rel oncogene and the developmentally regulated dorsal gene of Drosophila melanogaster $(30,31)$. The v-rel oncogene was first identified in reticuloendotheliosis virus strain $\mathrm{T}(\mathrm{Rev}-\mathrm{T})$, an avian retrovirus that causes fatal lymphoid tumors in young birds. The dorsal gene is one of a number of maternal effect genes that serve to establish polarity of the developing embryo. Recent studies have identified at least four distinct cellular proteins (p50, p55, p75, and p85) in human T-lymphoid and nonlymphoid cells that display specific and inducible binding to the $\kappa \mathrm{B}$ enhancer motif (32). Although the induction of these proteins appears to be differentially regulated during $\mathrm{T}$-cell activation, each of these proteins is immunologically related to $v-\operatorname{Rel}(33)$. The largest of these four $\kappa \mathrm{B}$-binding proteins ( $\mathrm{p85}$ ) corresponds to the cellular homologue of v-Rel, designated c-Rel. While Tax appears to activate each of the four members of the NF- $\kappa$ B family of proteins, the predominant Tax-inducible protein is c-Rel. Interestingly, one component of the activation of C-Rel by Tax invovles the transcriptional induction of c-rel gene expression. Thus, regulation of the NF- $\kappa$ B family of proteins is not controlled exclusively by post-translational cytoplasmic/nuclear partitioning.

The precise molecular mechanism or mechanisms by which Tax activates the CREB/ATF and NF- $\mathrm{BB}$ transcription factor pathways remain elusive. However, recent studies have identified tax gene mutants that functionally distinguish transactivation through these two host transcription factor pathways (34). Specifically, five mutants affecting two different hydrophobic regions of Tax were found to effectively trans-activate NF- $\kappa$ B-responsive promoters while failing to significantly activate $\mathrm{CREB} / \mathrm{ATF}$-responsive promoters. Conversely, a single tax mutant was shown to effectively trans-activate CREB/ ATF-responsive promoters while lack the ability to induce the nuclear expression of NF- $\kappa$ B or trans-activate NF- $\kappa$ B-responsive promoters. The identification of these phenotypically distinct tax mutants demonstrates that Tax activation of CREB/ ATF and NF- $\kappa$ B-responsive promoters proceeds via different intermediate signal transduction pathways and suggests that this activation is mediated by separate peptide domains within the Tax protein. These mutants should prove valuable in future studies of the molecular mechanisms of Tax trans- activation and may provide important insights into the role of these host transcription factor pathways in Tax-mediated cellular transformation.

\section{The Rex protein: a regulator of $H T L V-I$ structural gene expression}

The rex gene product is a $27-\mathrm{kD}$ phosphorylated protein localized in the nuclei and predominantly the nucleoli of expressing 
cells. In contrast to Tax, Rex does not appear to directly regulate transcription. Rather, Rex functions to increase the expression of viral structural and enzymatic proteins by promoting the cytoplasmic expression of the incompletely spliced $\mathrm{gag} / \mathrm{pol}$ and $e n v$ mRNAs, thereby allowing their translation (35) (Fig. 3). In the absence of Rex, these unspliced or singly spliced mRNAs remain sequestered in the nucleus where they are either completely spliced or degraded. Rex likely functions to either activate nuclear export of these partially processed viral mRNAs or promote the disassembly of spliceosomes engaging these viral transcripts, thereby allowing their export to the cytoplasm by default. By increasing the cytoplasmic expression of unspliced and singly spliced mRNAs, Rex also indirectly inhibits the expression of the doubly spliced tax/rex mRNA. As discussed below, this negative regulation of tax and rex gene expression by Rex may have important implications for the establishment and maintenance of viral latency. The action of Rex is sequence specific. The target for Rex action has been localized to the $3^{\prime}$ LTR and corresponds to a large and energetically stable RNA stem-loop structure termed the Rex response element (RexRE) $(36,37)$. The RexRE functions in a strictly orientation-dependent but position-independent manner within the viral mRNA.

In many respects, the function of the rev gene product of HIV-1 is analogous to that of Rex. Like Rex, Rev promotes the cytoplasmic appearance of incompletely spliced viral mRNAs encoding the HIV-1 structural and enzymatic proteins. Similarly, the Rev response element (RevRE) corresponds to a large and energetically stable RNA stem-loop structure. However, in contrast to the RexRE, the RevRE is located in an intronic

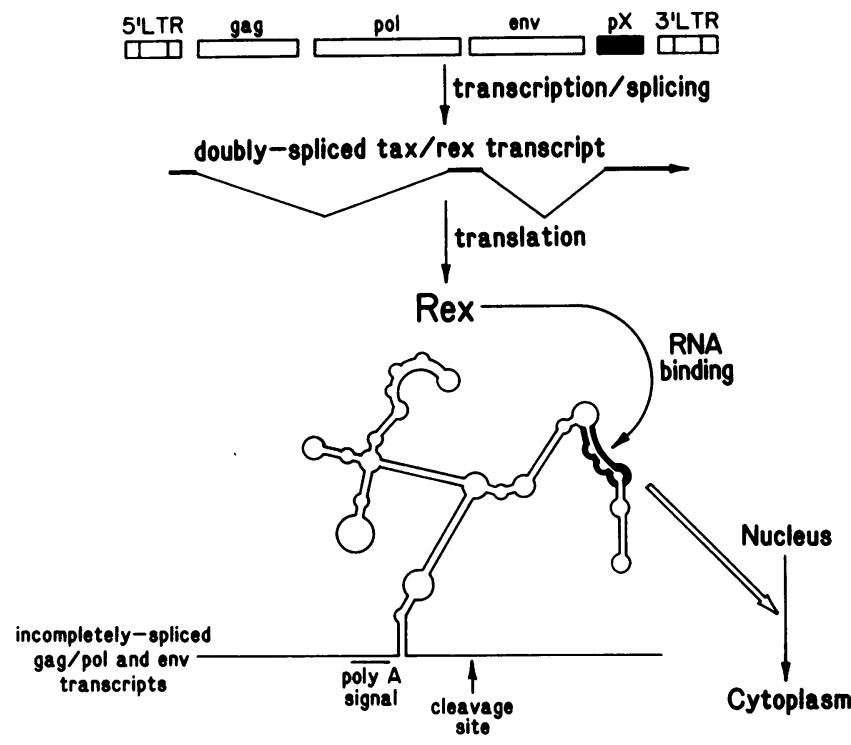

Figure 3. Rex action involves binding to its RNA response element. The predicted structure of the large and energetically stable RexRE is shown schematically. The $\mathrm{pX}$ derived Rex protein specifically binds to the RexRE, and this binding has been localized to a specific stem region (bold lines). Although the RexRE is present in all viral transcripts, Rex selectively promotes the cytoplasmic expression of incompletely-spliced $\mathrm{gag} / \mathrm{pol}$ and $e n v$ transcripts. In addition, the stem-loop structure of the RexRe serves an unexpected role in the $3^{\prime}$ processing of all viral transcripts by approximating the polyadenylation signal and the site of $3^{\prime}$ cleavage and polyadenylation. position within the HIV-1 env gene and therefore is present only in those partially spliced mRNA species that are regulated by Rev. Although the Rev and Rex proteins and their respective RNA response element lack significant homology, the HTLV-I Rex protein can functionally replace the HIV-1 Rev protein. This surprising genetic complementation is sufficiently complete to allow Rex rescue of the replication of rev defective HIV-1 proviruses (38). Of note, while Rex can function through both the Rex and the Rev response elements, Rev is unable to act through the RexRE. This nonreciprocal pattern of complementation displayed by Rex and Rev is most easily explained by a model involving the direct interaction of these trans-regulatory proteins with their respective RNA response elements. Consistent with this interpretation, recent studies have demonstrated that recombinant Rex protein binds directly and specifically to both the RexRE and RevRE in vitro (39). Conversely, Rev binds to the $\operatorname{RevRE}(40,41)$ but does not appear to interact with the RexRE (39).

In addition to its critical role in mediating Rex responsiveness, the RexRE also serves an unexpected function in the $3^{\prime}$ cleavage and polyadenylation of all HTLV-I viral transcripts (42). The HTLV-I polyadenylation signal is separated from the site of $3^{\prime}$ cleavage by more than 250 nucleotides (Fig. 3). This spatial separation is unprecedented among other viral or cellular polyadenylated mRNAs for which separation of the polyadenylation signal and $3^{\prime}$ cleavage site by more than 30 nucleotides abolishes $3^{\prime}$ RNA processing. Strikingly, the sequences between the polyadenylation signal and $3^{\prime}$ cleavage site correspond to the RexRE. The stem-loop structure of the RexRE juxtaposes the polyadenylation signal and a highly conserved element downstream of the polyadenylation site, and thereby allows the cooperative and stable binding of two cellular factors essential for $3^{\prime}$ end formation. The stable binding of these two cellular factors commits the transcript to $3^{\prime}$ RNA processing. Mutations of the RexRE which disrupt its secondary structure result in the loss of polyadenylation. Conversely, reconstitution of the predicted stem-loop structure with a different sequence restores effective polyadenylation. Of note, these permissive effects of the RexRE in the polyadenylation reaction do not require nor are they influenced by the presence of Rex.

Mutational analyses of the Rex protein have revealed the presence of at least two functionally distinct peptide domains. One domain mediates both nuclear/nucleolar targeting of Rex and RNA-binding to the RexRE and the RevRE. In contrast, a second domain appears to be required for the effector function of Rex. (43). The nuclear/nucleolar localization domain contains several positively charged arginine residues and bears considerable homology to a consensus RNA-binding motif first identified in various bacteriophage anti-termination proteins (44). Mutants affecting residues within this positively charged domain neither localize to the nuclear compartment nor bind to either the RexRE or the RevRE in vitro (39). The overexpression of these inactive mutants does not inhibit the activity of the wild-type Rex protein. In contrast, mutations affecting residues within the effector domain of Rex are both biologically inactive and effectively interfere with the activity of the wild-type Rex protein. Therefore, these mutants are termed dominant-negative or trans-dominant. These trans-dominant rex mutants retain the ability to specifically interact with the RexRE (39), however, the precise basis for trans-dominant repression by these Rex mutants remains unknown. One possible 
model is that the trans-dominant mutants compete for binding sites on the RexRE. Alternatively, Rex may function as a multimer and the trans-dominant mutants of Rex may form biologically inactive mixed multimers with the wild-type protein, thereby inhibiting Rex action. Notably, these rex trans-dominant mutants function as effective inhibitors in the HTLV-I, HTLV-II, and HIV-1 viral systems (43), raising the possibility of their future use as therapeutic agents for the prevention and/ or treatment of the diseases associated with these pathogenic retroviruses.

\section{Summary and future directions}

The Tax and Rex proteins play pivotal roles in the regulation of HTLV-I gene expression. Our current understanding of the functions and mechanisms of action of these two trans-regulatory proteins supports the following model of the HTLV-I life cycle. Immediately after infection of $\mathrm{T}$ cells, transcription of viral genes is dependent on the interaction of various cellular factors with the transcriptional regulatory sequences present in the LTR. In the absence of Rex, only completely spliced viral transcripts encoding Tax and Rex reach the cytoplasm. Since Tax may be preferentially translated from these completely spliced transcripts, initially Tax and only low levels of Rex would be produced. Tax-mediated trans-activation of the HTLV-I LTR would ensue leading to abundant tax/rex mRNA in the cytoplasm and the gradual accumulation of Rex. At some threshold level, Rex would promote the appearance of genomic and singly spliced viral transcripts in the cytoplasm. Translation of the viral structural and enzymatic gene products from these partially spliced viral mRNAs would then occur and allow for virion assembly and release. However, by increasing the cytoplasmic expression of these incompletely spliced viral transcripts, Rex would indirectly inhibit the expression of the doubly spliced tax/rex mRNA. This negative regulation of Tax and Rex expression by Rex would in turn lead to the decreased expression of all viral genes, and potentially result in the establishment of a latently infected state. Subsequent similar bursts of viral production might result from the immune activation of the latently infected T cell, since the HTLV-I LTR responds to some of the same physiological stimuli that mediate normal $\mathrm{T}$-cell activation. Therefore, while the activation of the latently infected cell may represent the switch to turn on viral gene expression, the differential regulation of viral gene expression by Rex may serve to orchestrate controlled periods of virion formation and subsequent reestablishment of viral latency. This strategy of chronic latent infection coupled with episodic virion production would result in the gradual accumulation of latently infected cells. This type of life cycle might also facilitate HTLV-I escape from immune surveillance, as transient highlevel production of virions would minimize the ability of the host to mount an effective immune response. How this proposed life cycle of HTLV-I results in the development of the adult $\mathrm{T}$-cell leukemia remains unclear. However, cellular transformation may represent an effective strategy for proviral replication since rapid cellular division of the leukemic clones results in the concomitant replication of the integrated provirus in the absence of proviral gene expression (45).

Several emerging lines of evidence suggest that Tax plays a central role in HTLV-I mediated leukemogenesis. The ability of Tax to trans-activate the genes for IL-2 and the $\alpha$ chain of the IL-2 receptor suggest that this viral trans-regulatory protein may initiate the leukemogenic process by promoting the deregulated polyclonal proliferation of these virally infected $\mathrm{T}$ cells. The long period of clinical latency that precedes the development of leukemia, and the observation that leukemic cells from ATLL patients are monoclonal suggest that additional cellular events are required for the development of the full malignant phenotype. Currently, a satisfactory animal model of the leukemic phase of ATLL is lacking, and the nature of these additional events remains conjectural. However, results from several experimental systems indicate that the stable expression of tax may lead to the transformation of nonlymphoid cells. Why no lymphoid malignancies have been detected remains puzzling. Further studies of the HTLV-I trans-regulatory proteins will likely begin to provide the answers to these questions, as well as increase our understanding of the processes involved in malignant transformation of human $\mathrm{T}$ cells.

\section{Acknowledgments}

We thank Jerome Kim, Dean Ballard, and Yasmath Ahmed for critical comments regarding this manuscript.

M. R. Smith is supported by the Medical Scientist Training Program.

\section{References}

1. Cullen, B. R., and W. C. Greene. 1989. Regulatory pathways governing HIV-1 replication. Cell. 58:423-426.

2. Poiesz, B. F., F. W. Ruscetti, A. F. Gazdar, P. A. Bunn, J. D. Minna, and R. C. Gallo. 1980. Detection and isolation of type $C$ retrovirus particles from fresh cultured lymphocytes of a patient with cutaneous T-cell lymphoma. Proc. Natl. Acad. Sci. USA. 77:7415-7419.

3. Yoshida, M., I. Miyoshi, and Y. Hinuma. 1982. Isolation and characterization of retrovirus from cell lines of human adult T-cell leukemia and its implication in the disease. Proc. Natl. Acad. Sci. USA. 79:2031-2035.

4. Kim, J. H., and D. T. Durack. 1988. Manifestations of human T-lymphotropic virus type I infection. Am. J. Med. 84:919-927.

5. Gessain, A., F. Barin, J. C. Vernant, O. Gout, L. Maurs, A. Calender, and G. de The. 1985 Antibodies to the human T lymphotropic virus type-1 in patients with tropical spastic paraparesis. Lancet. 2:407-410.

6. Osame, M., K. Usuku, N. Ijichi, H. Amitani, A. Igata, M. Matsumoto, and H. Tara. 1986. HTLV-I associated myelopathy, a new clinical entity. Lancet. 1:1031-1032.

7. Sarma, P. S., and J. Gruber. 1990. Human T-cell lymphotropic viruses in human diseases. J. Natl. Cancer Inst. 82:1100-1106.

8. Kalyanaraman, V. S., M. G. Sarngadharan, M. Robert-Guroff, I. Miyoshi, D. Blayney, D. Golde, and R. C. Gallo. 1982. A new subtype of human T-cell leukemia virus (HTLV-II) associated with a T-cell variant hairy cell leukemia. Science (Wash. DC). 218:571-573.

9. Rosenblatt, J. D., D. W. Golde, W. Wachsman, A. Jacobs, G. Schmidt, S Quan, J. C. Gasson, and I. S. Y. Chen. 1986. A second HTLV-II isolate associated with atypical hairy cell leukemia. N. Engl. J. Med. 315:372-375.

10. Lee, H., P. Swanson, V. S. Shorty, J. A. Zack, J. D. Rosenblatt, and I. S. Y. Chen. 1989. High rate of HTLV-II infection in seropositive IV drug abusers from New Orleans. Science (Wash. DC). 244:471-475.

11. Seiki, M., S. Hattori, and M. Yoshida. 1982. Human adult T-cell leukemia virus: molecular cloning of the provirus DNA and the unique terminal structure. Proc. Natl. Acad. Sci. USA. 79:6899-6902.

12. Seiki, M., R. Eddy, T. B. Shows, and M. Yoshida. 1984. Nonspecific integration of the HTLV provirus genome into adult T-cell leukemia cells. Nature (Lond.). 309:640-642.

13. Waldmann, T. A., W. C. Greene, P. S. Sarin, C. Saxinger, D. W. Blayney, W. A. Blattner, C. K. Goldman, K. Bongiovanni, S. Sharrow, J. Depper, et al. 1984. Functional and phenotypic comparison of human $T$ cell leukemia/lymphoma virus negative Sezary leukemia, and their distinction using anti-Tac. $J$. Clin. Invest. 73:1711-1718.

14. Krönke, M., W. J. Leonard, J. Depper, and W. C. Greene. 1985. Deregulation of interleukin-2 receptor gene expression in HTLV-I-induced adult T-cell leukemia. Science (Wash. DC). 228:1215-1217.

15. Chen, I. S. Y., D. J. Slamon, J. D. Rosenblatt, N. P. Shah, S. G. Quan, and W. Wachsman. 1985. The $x$ gene is essential for HTLV replication. Science (Wash. DC). 229:54-58. 
16. Sodroski, J., C. Rosen, W. C. Goh, and W. Haseltine. 1985. A transcriptional activator protein encoded by the $\mathrm{x}$-lor region of the human $\mathrm{T}$-cell leukemia virus. Science (Wash. DC). 228:1430-1434.

17. Inoue, J., M. Seiki, T. Taniguchi, S. Tsuru, and M. Yoshida. 1986. Induction of interleukin- 2 receptor gene expression by $\mathrm{p} 40^{\mathrm{x}}$ encoded by human T-cell leukemia virus type I. EMBO (Eur. Mol. Biol. Organ.) J. 5:2883-2888.

18. Cross, S. L., M. B. Feinberg, J. B. Wolf, N. J. Holbrook, F. Wong-Staal, and W. J. Leonard. 1987. Regulation of the human interleukin-2 receptor $\alpha$ chain promoter: activation of a nonfunctional promoter by the transactivator gene of HTLV-I. Cell. 49:47-56.

19. Fujii, M., P. Sassone-Corsi, and I. M. Verma. 1988. c-fos promoter transactivation by the tax $x_{1}$ protein of human T-cell leukemia virus type I. Proc. Natl. Acad. Sci. USA. 85:8526-8530.

20. Böhnlein, E., M. Siekevitz, D. W. Ballard, J. W. Lowenthal, L. Rimsky, H. Bogerd, J. Hoffman, Y. Wano, B. R. Franza, and W. C. Greene. 1988. Stimulation of the HIV-1 enhancer by the HTLV-I tax gene product involves the action of inducible cellular proteins. J. Virol. 63:1578-1586.

21. Grassman, R., C. Dengler, I. Muller-Fleckenstein, B. Fleckenstein, K. McGuire, M.-C. Dokhlear, J. G. Sodroski, and W. A. Haseltine. 1989. Transformation to continuous growth of primary human $\mathrm{T}$ lymphocytes by human $\mathrm{T}$-cell leukemia virus type I X-region genes transduced by a Herpesvirus saimiri vector. Proc. Natl. Acad. Sci. USA. 86:3351-3355.

22. Hinrichs, S. H., M. Nerenberg, R. K. Reynolds, G. Khoury, and G. Jay. 1987. A transgenic mouse model for human neurofibromatosis. Science (Wash. DC). 237:1340-1343.

23. Pozzatti, R., J. Vogel, and G. Jay. 1990. The human T-lymphotropic virus type I tax gene can cooperate with the ras oncogene to induce neoplastic transformation of cells. Mol. Cell. Biol. 10:413-417.

24. Tanaka, A., C. Takahashi, S. Yamaoka, T. Nosaka, M. Maki, and M. Hatanaka. 1990. Oncogenic transformation by the tax gene of human T-cell leukemia virus type I in vitro. Proc. Natl. Acad. Sci. USA. 87:1071-1075.

25. Jeang, K-T., S. G. Widen, O. J. Semmes, and S. H. Wilson. 1990. HTLV-I transactivator protein, Tax, is a trans-repressor of the human $\beta$-polymerase gene. Science (Wash. DC). 247:1082-1084.

26. Jeang, K-T., I. Boros, J. Brady, M. Radonovich, and G. Khoury. 1988. Characterization of cellular factors that interact with the human T-cell leukemia virus type I p40x-responsive 21-base-pair sequence. J. Virol. 62:4499-4509.

27. Lenardo, M. J., and D. Baltimore. 1989. NF- $\kappa$ B: a pleiotropic mediator of inducible and tissue-specific gene control. Cell. 58:227-229.

28. Baeuerle, P., and Baltimore, D. 1988. I $\kappa$ B: a specific inhibitor of the NF- $\kappa B$ transcription factor. Science (Wash. DC). 242:540-546.

29. Ghosh, S., and D. Baltimore. 1990. Activation in vitro of NF- $\kappa$ B by phosphorylation of its inhibitor $I_{\kappa} B$. Nature (Lond.). 344:678-682.

30. Ghosh, S., A. M. Gifford, L. R. Riviere, P. Tempst, G. P. Nolan, and D. Baltimore. 1990. Cloning of the p50 DNA binding subunit of NF- $\kappa$ B: homology to rel and dorsal. Cell. 62:1019-1029.
31. Kieran, M., V. Blank, F. Logeat, J. Vandekerckhove, F. Lottspeich, O. Le Bail, M. B. Urban, P. A. Baeuerle, and A. Israël. 1990. The DNA binding subunit of NF- $\mathrm{KB}$ is identical to factor $\mathrm{KBF} 1$ and homologous to the rel oncogene product. Cell. 62:1007-1018.

32. Molitor, J. A., W. A. Walker, S. Doerre, D. W. Ballard, and W. C. Greene. 1990. NF- $\mathrm{B}$ : a family of inducible and differentially expressed enhancer binding proteins in human T-cells. Proc. Natl. Acad. Sci. USA. 87:10028-10032.

33. Ballard, D. W., W. Walker, S. Doerre, P. Sista, J. A. Molitor, E. P. Dixon, N. J. Peffer, M. Hannink and W. C. Greene. 1990. The v-rel oncogene encodes a $\kappa \mathrm{B}$ enhancer binding protein that inhibits NF- $\kappa \mathrm{B}$ function. Cell. 63:803-814.

34. Smith, M. R., and W. C. Greene. 1990. Identification of HTLV-I tax trans-activator mutants exhibiting novel transcriptional phenotypes. Genes Dev. 4:1875-1885.

35. Hidaka, M., J. Inoue, M. Yoshida, and M. Seiki. 1988. Post-transcriptional regulator (rex) of HTLV-I initiates expression viral structural proteins, but supresses expression of regulatory proteins. 1988. EMBO (Eur. Mol. Biol. Organ.) J. 7:519-523.

36. Hanly, S. M., L. T. Rimsky, M. H. Malim, J. H. Kim, J. Hauber, M. Duc Dudon, S.-Y. Le, J. V. Maizel, B. R. Cullen, and W. C. Greene. 1989. Comparative analysis of the HTLV-I Rex and HIV-1 Rev trans-regulatory proteins and their RNA response elements. Genes Dev. 3:1534-1544.

37. Ahmed, Y. F., S. Hanly, M. H. Malim, B. R. Cullen, and W. C. Greene 1990. Structure-function analysis of the HTLV-I Rex and HIV-1 Rev RNA response elements: insights into the mechanism of Rex and Rev action. Genes Dev. 4:1014-1022.

38. Rimsky, L. T., J. Hauber, M. Dukovich, M. H. Malim, A. Langlois, B. R. Cullen, and W. C. Greene. 1988. Functional replacement of the HIV Rev protein by the HTLV-I Rex protein. Nature (Lond.). 335:738-740.

39. Bogerd, H. P., G. L. Huckaby, Y. F. Ahmed, and W. C. Greene. The HTLV-I Rex protein binds directly to the HTLV-I Rex and HIV-1 Rev response elements. Clin. Res. in press.

40. Zapp, M. L., and M. R. Green. 1989. Sequence-specific RNA binding by the HIV-1 Rev protein. Nature (Lond.). 342:714-716.

41. Daly, T. J., K. S. Cook, G. S. Gray, T. E. Maione and J. R. Rusche. 1989. Specific binding of HIV-1 recombinant Rev protein to the Rev-responsive element in vitro. Nature (Lond.). 342:816-819.

42. Ahmed, Y. F., G. M. Gilmartin, J. R. Nevins and W. C. Greene. The HTLV-I Rex response element mediates a novel form of mRNA polyadenylation. Cell. In press.

43. Rimsky, L. T., M. Duc Dodon, E. P. Dixon and W. C. Greene. 1989. Mutational analysis of the HTLV-I Rex trans-activator: trans-dominant inactivation of HTLV-I and HIV-1 gene expression. Nature (Lond.). 341:453-456.

44. Lazinski, D., E. Grzadzielska, and A. Das. 1989. Sequence-specific recognition of RNA hairpins by bacteriophage antitierminators requires a conserved arginine-rich motif. Cell. 59:207-218.

45. Green, P. L., and I. S. Y. Chen. 1990. Regulation of human T cell leukemia virus expression. FASEB (Fed. Am. Soc. Exp. Biol.) J. 4:169-175. 